\section{BRAZIULIAN JOURNAL \\ OF MIEDICAL AND BIOLOGICAL RESFARCH}

www.bjournal.com.br
ISSN 0100-879X

Volume 43 (11) 1010-1134 November 2010

BIOMEDICAL SCIENCES

AND

CLINICAL INVESTIGATION

Braz J Med Biol Res, November 2010, Volume 43(11) 1102-1108

doi: 10.1590/S0100-879X2010007500100

Acute kidney injury in AIDS: Frequency, RIFLE classification and outcome

G.B. Silva Júnior, A.B. Libório, R.M.S. Mota, K.L.S. Abreu, A.E.B. Silva, S.M.H.A. Araújo and E.F.

Daher

The Brazilian Journal of Medical and Biological Research is partially financed by
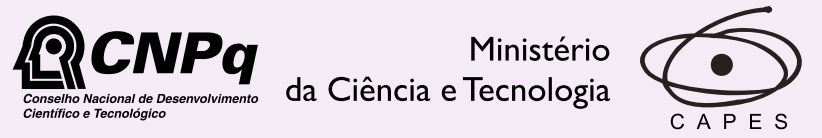

Ministério da Educação

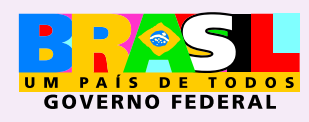

DFAPESP

Institutional Sponsors

Hotsite of proteomics metabolomics developped by: 


\title{
Acute kidney injury in AIDS: frequency, RIFLE classification and outcome
}

\author{
G.B. Silva Júnior ${ }^{1}$, A.B. Libório ${ }^{1,2}$, R.M.S. Mota ${ }^{3}$, K.L.S. Abreu¹, \\ A.E.B. Silva ${ }^{1}$, S.M.H.A. Araújo ${ }^{1}$ and E.F. Daher ${ }^{1}$ \\ ${ }^{1}$ Divisão de Nefrologia, Hospital Universitário Walter Cantídio, Faculdade de Medicina, \\ Universidade Federal do Ceará, Fortaleza, CE, Brasil \\ ${ }^{2}$ Divisão de Nefrologia, Departamento de Medicina, Universidade de Fortaleza, Fortaleza, CE, Brasil \\ ${ }^{3}$ Departamento de Estatística, Centro de Ciências, Universidade Federal do Ceará, Fortaleza, CE, Brasil
}

\begin{abstract}
The objective of the present study was to evaluate the characteristics of acute kidney injury (AKI) in AIDS patients and the value of RIFLE classification for predicting outcome. The study was conducted on AIDS patients admitted to an infectious diseases hospital in Brazil. The patients with AKI were classified according to the RIFLE classification: R (risk), I (injury), F (failure), L (loss), and E (endstage renal disease). Univariate and multivariate analyses were used to evaluate the factors associated with AKI. A total of 532 patients with a mean age of $35 \pm 8.5$ years were included in this study. AKI was observed in $37 \%$ of the cases. Patients were classified as "R" (18\%), "l" (7.7\%) and "F" (11\%). Independent risk factors for AKI were thrombocytopenia (OR = 2.9, 95\% $\mathrm{Cl}=1.5-5.6, \mathrm{P}<0.001)$ and elevation of aspartate aminotransferase (AST) $(\mathrm{OR}=3.5,95 \% \mathrm{Cl}=1.8-6.6, \mathrm{P}<0.001)$. General mortality was $25.7 \%$ and was higher among patients with AKI (40.2 vs 17\%, P < 0.001). AKI was associated with death and mortality increased according to RIFLE classification - "R" (OR 2.4), "I" (OR 3.0) and "F" (OR 5.1), P < 0.001. AKI is a frequent complication in AIDS patients, which is associated with increased mortality. RIFLE classification is an important indicator of poor outcome for AIDS patients.
\end{abstract}

Key words: Acute kidney injury; HIV; AIDS; Prognosis; Mortality; RIFLE

\section{Introduction}

Acquired immunodeficiency syndrome (AIDS) is a public health problem that affects millions of people in the world. Renal diseases have been described in AIDS and can be caused by multiple factors, including opportunistic infections, neoplasms and drugs (1). Mortality is reported to increase when renal diseases develop in AIDS patients (2).

Acute kidney injury (AKI) is a frequent complication that occurs in 10 to $30 \%$ of patients with AIDS $(3,4)$. Common causes of AKI in these patients include use of antiretroviral drugs, volume depletion, sepsis, and hepatic disease (5).

The RIFLE classification - R (risk), I (injury), F (failure), $L$ (loss), and $E$ (end-stage renal disease) for AKI in HIV-infected patients presented a significant association with mortality in a recent study, suggesting that AKI is an important risk factor for death in HIV-infected patients (6). The aim of the present study was to evaluate the frequency, clinical features, RIFLE classification and outcome of a group of AIDS patients.

\section{Patients and Methods}

\section{Study subjects}

Across-sectional study was conducted on 532 consecutive patients with a confirmed diagnosis of HIV infection. All patients were admitted to the São José Infectious Diseases Hospital, a large tertiary hospital in Fortaleza City, Northeast of Brazil, during the period between January 1995 and July 2006. The inclusion criteria were all patients with opportunist infections associated with confirmed HIV infection as determined by indirect immunofluorescence and/or enzyme-linked immunosorbent assay. The exclusion criteria were patients with preexisting chronic kidney disease, arterial hypertension, diabetes mellitus, and other co-morbidities that could chronically affect renal function. All reported cases met the 1987 AIDS case definition of the Centers for Disease Control and Prevention (USA).

Correspondence: G.B. Silva Júnior, Rua 25 de março, 997, 60060-120 Fortaleza, CE, Brasil. Fax: +55-85-3239-4660/3366-8611.

E-mail: geraldobezerrajr@yahoo.com.br or ef.daher@uol.com.br

Received February 3, 2010. Accepted September 21, 2010. Available online October 1, 2010. Published November 12, 2010. 
Clinical investigation included a medical record review of all clinical signs and symptoms at hospital admission, and use of antiretroviral drugs.

\section{Data collection}

Clinical investigation included a medical record review of all demographic characteristic, clinical signs and symptoms presented by each patient at hospital admission, and use of antiretroviral drugs. Laboratory data included the assessment of serum urea, creatinine, transaminases, direct and indirect bilirubin, lactate dehydrogenase (LDH), blood count, platelets, CD4, viral load, and urinalysis.

\section{Definitions}

Patients were classified according to RIFLE criteria on the basis of creatinine criteria, since most patients did not have urinary volume data in the medical charts (7-9). Baseline creatinine was considered to be the value determined at hospital admission or the lowest creatinine level before admission. Anemia was defined as hemoglobin $<12$ $\mathrm{g} / \mathrm{dL}$, thrombocytopenia as platelet count $<100,000 / \mathrm{mm}^{3}$, leukocytosis as white blood count $>12,000 / \mathrm{mm}^{3}$, and elevation of liver enzymes such as aspartate aminotransferase (AST) and/or alanine aminotransferase $(A L T)>2$ times the normal value, CD4 $<200 / \mu \mathrm{L}$, and viral load $>10,000$ copies/ $\mathrm{mL}$. Proteinuria was considered to be positive when a urine dipstick indicated 1+ or more, leukocyturia was considered to be the presence of 5 or more cells per high power field (100X) and hematuria as the presence of two or more white blood cells per high power field (100X) or positivity to a urine dipstick (1+ or more).

\section{Patient groups}

Patients were divided into four groups: patients with and without AKI, survivors, and nonsurvivors. Factors associated with $\mathrm{AKI}$ and death were investigated by univariate and multivariate analysis.

\section{Ethics}

The study protocol was reviewed and approved by the Ethics Committees of the University Hospital Walter Cantídio and São José Hospital of Infections Diseases in Fortaleza.

\section{Statistical analyses}

Statistical analyses were performed with the programs SPSS 10.0 for Windows (SPSS Inc., USA) and Epi-Info 6.04b (Centers for Disease Control and Prevention, Atlanta, GA, USA), and consisted of univariate and multivariate analyses. The two groups of patients were compared by the Student $t$-test, Fischer exact test, Mann-Whitney test, and chi-square test, when appropriate. Alogistic regression model was built for quantitative variables, and association measures were calculated (adjusted odds ratio), with a $95 \%$ confidence interval. A multivariate analysis was per- formed for the investigation of independent risk factors for $\mathrm{AKI}$, and included the factors that presented a $<20 \%$ level of significance in the univariate analysis (Mann-Whitney and chi-square tests). Values below 5\% $(P<0.05)$ were considered to be statistically significant.

\section{Results}

\section{Characteristics and signs and symptoms of patients}

A total of 532 consecutive AIDS patients (77\% males) with an average age of $35 \pm 8.5$ years (range: 19 to 71 years) were included in the study. The more frequent comorbidities were histoplasmosis (33\%), tuberculosis (13\%), intestinal parasitosis (8\%), and pneumocystosis (5\%). The main clinical manifestations at admission were fever (74\%), cough (60\%), diarrhea (57\%), weight loss (56\%), vomiting $(40 \%)$, anorexia (38\%), adynamia (35\%), dyspnea (30\%), headache $(23 \%)$, and abdominal pain (20\%). Antiretroviral drugs were used by 247 patients $(46.4 \%)$ at admission.

\section{Laboratory findings}

Laboratory findings at admission of the 532 patients in this study showed hemoglobin $=9.7 \pm 2.6 \mathrm{~g} / \mathrm{dL}$, hematocrit $=28.8$ $\pm 7.7 \%$, white blood count $=6354 \pm 4662 / \mathrm{mm}^{3}$, lymphocytes $=$ $236 \pm 679 / \mathrm{mm}^{3}$, platelets $=175,216 \pm 116,253 / \mathrm{mm}^{3}$, urea $=51$ $\pm 54 \mathrm{mg} / \mathrm{dL}$, creatinine $=1.4 \pm 1.5 \mathrm{mg} / \mathrm{dL}, A S T=154 \pm 220 \mathrm{lU} / \mathrm{L}$, $\mathrm{ALT}=76 \pm 178 \mathrm{IU} / \mathrm{L}, \mathrm{CD} 4=$ count $155 \pm 194 / \mathrm{mm}^{3}$, and viral load $=289,120 \pm 748,203 / \mathrm{mm}^{3}$. Anemia was observed in 405 cases $(76.1 \%)$, leukopenia in $60(11.2 \%)$, thrombocytopenia in $146(27.4 \%)$, liver enzyme elevation in 127 (23.8\%), and CD4 count $<200 / \mathrm{mm}^{3}$ in 259 cases $(48.6 \%)$.

\section{Frequency of AKI in the study population and RIFLE classification}

AKI was observed at admission in 197 patients (37\%) who were classified according to RIFLE criteria as "Risk" (18\%), "Injury" (7.7\%), and "Failure" (11\%).

\section{Comparison between AKI and non-AKI patients}

Comparison of patients with and without AKI indicated a significant difference regarding gender (AKI was more frequent in males: 83.2 vs $16.8 \%, P=0.01$ ), clinical manifestations (fever, weight loss and diarrhea were more frequent in AKI patients) and use of antiretroviral drugs (more frequent among patients withoutAKI). The death rate was significantly higher in patients with AKI (40.2 vs 17\%, $\mathrm{P}<0.001)$. Clinical features comparing AKI and non-AKI patients are summarized in Table 1.

Laboratory tests demonstrated lower levels of hemoglobin and a higher incidence of anemia, leukopenia, leukocytosis and thrombocytopenia among AKI patients. Higher levels of AST, ALT, bilirubin, and LDH were also observed in AKI patients (Table 2).

Risk factors for AKI at admission determined by univariate analysis were: male gender, fever, weight loss, diarrhea, 
Table 1. Comparison of clinical characteristics of AIDS patients with and without acute kidney injury (AKI).

\begin{tabular}{lccccc}
\hline & AKI $(\mathrm{N}=197)$ & Non-AKI $(\mathrm{N}=335)$ & $\mathrm{P}$ & OR & $95 \% \mathrm{Cl}$ \\
\hline Age (years) & $35 \pm 9.0(19-71)$ & $34 \pm 8.2(19-64)$ & 0.26 & - & - \\
Gender & & & & & \\
$\quad$ Female & $33(16.8 \%)$ & $87(26 \%)$ & 0.01 & 1.7 & $1.1-2.7$ \\
$\quad$ Male & $164(83.2 \%)$ & $248(74 \%)$ & & & \\
Duration of HIV infection (months) & $17 \pm 29(0-120)$ & $19 \pm 25(0-156)$ & $<0.001$ & - & - \\
Signs and symptoms & & & & & \\
Fever & $159(80.7 \%)$ & $236(70.4 \%)$ & 0.01 & 1.7 & $1.1-2.6$ \\
Adynamia & $78(39.6 \%)$ & $107(31.9 \%)$ & 0.09 & - & - \\
Headache & $31(15.8 \%)$ & $92(27.5 \%)$ & 0.002 & 0.49 & $0.31-0.78$ \\
Anorexia & $72(36.5 \%)$ & $129(38.5 \%)$ & 0.71 & - & - \\
Cough & $122(61.9 \%)$ & $195(58.2 \%)$ & 0.41 & - & - \\
Weight loss & $124(62.9 \%)$ & $177(52.8 \%)$ & 0.02 & 1.5 & $1.0-2.1$ \\
Diarrhea & $124(62.9 \%)$ & $180(53.7 \%)$ & 0.04 & 1.4 & $1.0-2.0$ \\
Vomiting & $87(44.2 \%)$ & $127(37.9 \%)$ & 0.17 & - & - \\
$\quad$ Dyspnea & $66(33.5 \%)$ & $97(29 \%)$ & 0.28 & - & - \\
$\quad$ Abdominal pain & $40(20.3 \%)$ & $66(19.7 \%)$ & 0.91 & - & - \\
Use of antiretroviral drugs & $73(37.2 \%)$ & $174(51.9 \%)$ & $<0.001$ & 1.9 & $1.3-2.7$ \\
Death & $79(40.2 \%)$ & $57(17 \%)$ & $<0.001$ & 3.2 & $2.1-4.8$ \\
\hline
\end{tabular}

OR = odds ratio; $95 \% \mathrm{Cl}=95 \%$ confidence interval. $\mathrm{P}<0.05$ (Student $t$-test, Fischer exact test, MannWhitney test and chi-square test).

non-use of antiretroviral drugs, anemia, thrombocytopenia, and higher levels of AST and ALT, as shown in Table 3. Independent risk factors for AKI were: thrombocytopenia (OR $=2.9,95 \% \mathrm{Cl}=1.5-5.6, \mathrm{P}<0.001)$, and elevation of AST $(\mathrm{OR}=3.5,95 \% \mathrm{Cl}=1.8-6.6, \mathrm{P}<0.001)$.

\section{Mortality according to RIFLE classification}

The results of the RIFLE classification were associated significantly with mortality. Patients classified as "R" had a mortality of $33 \%$, while patients classified as "l" had a mortality of $39 \%$ and those classified as " $F$ " had a mortality of $51 \%(P=0.01)$. The use of antiretroviral drugs was more frequent among survivors.

The risk factors for mortality were significantly higher in patients with $\mathrm{AKI}(\mathrm{OR}=3.1,95 \% \mathrm{Cl}=2.1-4.7, \mathrm{P}<0.001)$ than in those without AKI. According to the RIFLE classification, patients with renal injury had a higher mortality risk "R" (OR = 2.4, 95\%Cl = 1.4-4.0, P < 0.001), "I" (OR = 3.0, $95 \% \mathrm{Cl}=1.5-6.0, \mathrm{P}<0.001)$ and "F" $(\mathrm{OR}=5.1,95 \% \mathrm{Cl}=$ $2.8-9.2, \mathrm{P}<0.001)$ than did patients without AKI.

In the group of patients with AKI $(\mathrm{N}=197)$, the independent risk factors for death were leukocytosis $(\mathrm{OR}=$ $4.7,95 \% \mathrm{Cl}=1.4-15.4, \mathrm{P}=0.01)$ and anemia $(\mathrm{OR}=4.8$, $95 \% \mathrm{Cl}=1.4-16.6, \mathrm{P}=0.01)$. General mortality $(\mathrm{N}=532)$ was $25.7 \%$, with a higher rate in the group with $\mathrm{AKI}(40.2 \%)$ and lower rate in patients without AKI $(17 \%, P<0.001)$. Patient outcome and RIFLE classification are illustrated in Figure 1.

\section{Discussion}

HIV-associated AKI was first described upon the introduction of AIDS, and was related to sepsis, hypotension and the use of nephrotoxic drugs (10-12). HIV-infected patients are at higher risk to develop AKI, and the possible risk factors are elevated viral load, low CD4 count, co-infection with hepatitis $\mathrm{C}$, diabetes, black race, male gender, and chronic kidney disease (13).

Due to the increase in the recognition of renal disease as a frequent complication of HIV infection, the Infectious Diseases Society of America recommends the evaluation of renal function in every patient with HIV at the time of diagnosis (3). With the advent of highly active antiretroviral therapy (HAART), the survival of HIV patients has improved, with an increase in the incidence of comorbidities, including AKI (14). In a study performed in London, the incidence of renal disease among HIV patients was 0.36 cases per 100 patients per year (12). In a recent study for the investigation of renal diseases associated with HIV infection, chronic kidney disease was detected in $1 / 3$ of 89 patients at autopsy, and there was evidence of renal diseases in $84 \%$ of the cases, a fact that highlights the great impact of kidney damage on HIV patients. The more frequently observed renal diseases were nephrosclerosis, HIV-associated nephropathy (HIVAN), and glomerulonephritis (15).

The present study investigated the occurrence of AKI among AIDS patients in a large hospital in Brazil. Studies 
Table 2. Comparison of laboratory tests at admission of AIDS patients with and without acute kidney injury (AKI).

\begin{tabular}{|c|c|c|c|c|c|}
\hline & $\mathrm{AKI}(\mathrm{N}=197)$ & Non-AKI $(\mathrm{N}=335)$ & $\mathrm{P}$ & OR & $95 \% \mathrm{Cl}$ \\
\hline Hemoglobin (g/dL) & $9.0 \pm 2.7(4.1-13.8)$ & $10 \pm 2.5(3.0-19.2)$ & $<0.001$ & - & - \\
\hline Hematocrit (\%) & $26 \pm 8.0(13.1-38.8)$ & $29 \pm 7.2(8.9-48.3)$ & $<0.001$ & - & - \\
\hline Anemia $(\mathrm{Hb}<12)$ & $164(88.2 \%)$ & $241(77.5 \%)$ & 0.003 & 2.1 & $1.2-3.6$ \\
\hline White blood count $\left(/ \mathrm{mm}^{3}\right)$ & $5768 \pm 4834(2350-7450)$ & $5518 \pm 3903(3200-6500)$ & 0.35 & - & - \\
\hline \multicolumn{6}{|l|}{ White blood count } \\
\hline$<3000$ & $61(33 \%)$ & $68(22 \%)$ & & & \\
\hline $3000-12,000$ & $105(56.8 \%)$ & $222(71.8 \%)$ & & & \\
\hline$>12,000$ & $19(10.3 \%)$ & $19(6.1 \%)$ & 0.003 & 1.8 & $1.2-2.8$ \\
\hline Lymphocytes $\left(/ \mathrm{mm}^{3}\right)$ & $220 \pm 108(140-380)$ & $246 \pm 119(150-460)$ & 0.26 & & \\
\hline Platelets $\left(/ \mathrm{mm}^{3}\right)$ & $136,330 \pm 107,339(57,000-178,000)$ & $198,435 \pm 115,131(116,250-259,750)$ & $<0.001$ & 2.8 & $1.9-4.2$ \\
\hline $\begin{array}{l}\text { Thrombocytopenia } \\
\quad(\text { platelets }<100,000)\end{array}$ & $80(44.7 \%)$ & $66(22 \%)$ & $<0.001$ & - & - \\
\hline Urea (mg/dL) & $79 \pm 66(31-109)$ & $32 \pm 34(20-35)$ & $<0.001$ & 6.0 & $1.6-21.8$ \\
\hline Creatinine (mg/dL) & $2.3 \pm 1.9(1.1-2.9)$ & $0.8 \pm 0.9(0.6-1.0)$ & $<0.001$ & 94.7 & $29.3-305.5$ \\
\hline Sodium (mEq/L) & $132.6 \pm 8.6(117-155)$ & $132.1 \pm 6.9(110-149)$ & 0.46 & - & - \\
\hline Potassium (mEq/L) & $4.1 \pm 1.8(2.1-6.8)$ & $3.6 \pm 0.7(2.2-5.4)$ & $<0.001$ & 0.5 & $0.2-0.7$ \\
\hline AST (IU/L) & $217 \pm 258(49-302)$ & $97 \pm 176(26-109)$ & $<0.001$ & & \\
\hline AST $>80$ & $85(62.5 \%)$ & $53(30.5 \%)$ & $<0.001$ & 3.8 & 2.3-6.1 \\
\hline ALT (IU/L) & $120 \pm 59(37-91)$ & $61 \pm 58(22-57)$ & $<0.001$ & & \\
\hline $\mathrm{ALT}>80$ & $44(33.6 \%)$ & $27(16 \%)$ & $<0.001$ & 2.6 & $1.5-4.6$ \\
\hline Direct bilirubin (mg/dL) & $3.44 \pm 3.65(0.1-9.6)$ & $1.34 \pm 1.93(0.1-9.0)$ & $<0.001$ & 2.6 & $1.3-5.3$ \\
\hline Indirect bilirubin (mg/dL) & $1.20 \pm 1.21(0.1-5.2)$ & $0.76 \pm 1.18(0.1-6.0)$ & $<0.001$ & 3.3 & $1.3-8.4$ \\
\hline LDH (IU/L) & $4131 \pm 4754(120-35,300)$ & $2148 \pm 3712(70-14,900)$ & $<0.001$ & 2.3 & $1.5-3.5$ \\
\hline 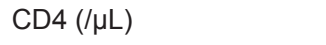 & $158 \pm 108(27-193)$ & $158 \pm 122(31-217)$ & 0.37 & - & - \\
\hline CD4 $<200 / \mu \mathrm{L}$ & $85(75.9 \%)$ & $174(72.5 \%)$ & 0.52 & - & - \\
\hline Viral load (copies/mL) & $257,813 \pm 468,907(3,100-262,500)$ & $303,617 \pm 847,595(4,400-230,000)$ & 0.69 & - & - \\
\hline $\begin{array}{l}\text { Viral load } \\
\quad>10,000 \text { copies } / \mathrm{mL}\end{array}$ & $63(67 \%)$ & $141(69.5 \%)$ & 0.68 & - & - \\
\hline \multicolumn{6}{|l|}{ Urinalysis } \\
\hline Proteinuria & $42(21.3 \%)$ & $71(21.1 \%)$ & 0.97 & - & - \\
\hline Hematuria & $36(18.2 \%)$ & $31(9.2 \%)$ & 0.002 & 2.1 & $1.3-3.6$ \\
\hline Leukocyturia & $34(17.1 \%)$ & $77(22.9 \%)$ & 0.11 & - & - \\
\hline
\end{tabular}

OR = odds ratio; $95 \% \mathrm{Cl}=95 \%$ confidence interval; $\mathrm{AST}=$ aapartate aminotransferase; $\mathrm{ALT}=$ alanine aminotransferase $. \mathrm{P}<0.05$ (Student $t$-test, Fischer exact test, Mann-Whitney test, and chi-square test).

Table 3. Risk factors for acute kidney injury in AIDS patients (univariate analysis).

\begin{tabular}{lccc}
\hline & OR & $95 \% \mathrm{Cl}$ & $\mathrm{P}$ \\
\hline Male gender & 1.7 & $1.1-2.1$ & 0.01 \\
Fever & 1.7 & $1.1-2.6$ & 0.01 \\
Weight loss & 1.5 & $1.0-2.1$ & 0.02 \\
Diarrhea & 1.4 & $1.0-2.0$ & 0.04 \\
Non-use of antiretroviral drugs & 1.9 & $1.3-2.7$ & $<0.001$ \\
Anemia & 2.1 & $1.2-3.6$ & $<0.001$ \\
Thrombocytopenia & 2.8 & $1.9-4.2$ & $<0.001$ \\
AST elevation & 3.8 & $2.3-6.1$ & $<0.001$ \\
ALT elevation & 2.6 & $1.5-4.6$ & $<0.001$ \\
\hline
\end{tabular}

OR = odds ratio; $95 \% \mathrm{Cl}=95 \%$ confidence interval; $\mathrm{AST}=$ aspartate aminotransferase; ALT = alanine aminotransferase. $\mathrm{P}<0.05$ (logistic regression). regarding this issue are rare, and this is the first and largest study about AIDS-associated AKI in Brazil. LagunaTorres et al. (16) studied 119 AIDS patients admitted to a teaching hospital in Southeast Brazil, with a mean age of 33 years, and found serum creatinine levels higher than 3 $\mathrm{mg} / \mathrm{dL}$ in $12.2 \%$ of cases. Electrolyte abnormalities were also found, including hyponatremia (61\%), hypernatremia (7\%), hypokalemia (24\%), and hyperkalemia (7\%). Proteinuria higher than $1 \mathrm{~g} /$ day was found in 7 cases $(5.8 \%)$. In a recent study on 400 Nigerian AIDS patients, Emem et al. (17) found evidence for renal disease (defined as at least " $1+$ ", albuminuria or serum creatinine higher than $1.4 \mathrm{mg} /$ $\mathrm{dL}$ ) in $31.1 \%$ of cases, which is similar to our findings.

The main signs and symptoms observed among the 
patients included in the present study were fever, cough, diarrhea, weight loss, vomiting, anorexia, adynamia, and dyspnea. Some of these manifestations, such as diarrhea and vomiting, could lead to the development of AKI. Use of antiretroviral drugs was observed in $46 \%$ of the cases, and it was less frequent among patients with AKI, suggesting a protective effect of the specific HIV treatment against the occurrence of AKI. Past studies have shown that the use of HAART can prevent the development of HIVAN and retards the progression of renal disease $(1,12)$.

Renal disease in HIV can be asymptomatic and progress slowly to chronic kidney disease (18). The most common cause of renal disease in HIV is HIVAN, and the main manifestation is proteinuria, which is in the nephrotic range in a considerable number of cases, and elevation in serum creatinine (18).

$\mathrm{AKI}$ was observed in a high percentage of patients at hospital admission $(37 \%)$. This incidence is similar to that reported in other studies $(6,17)$.

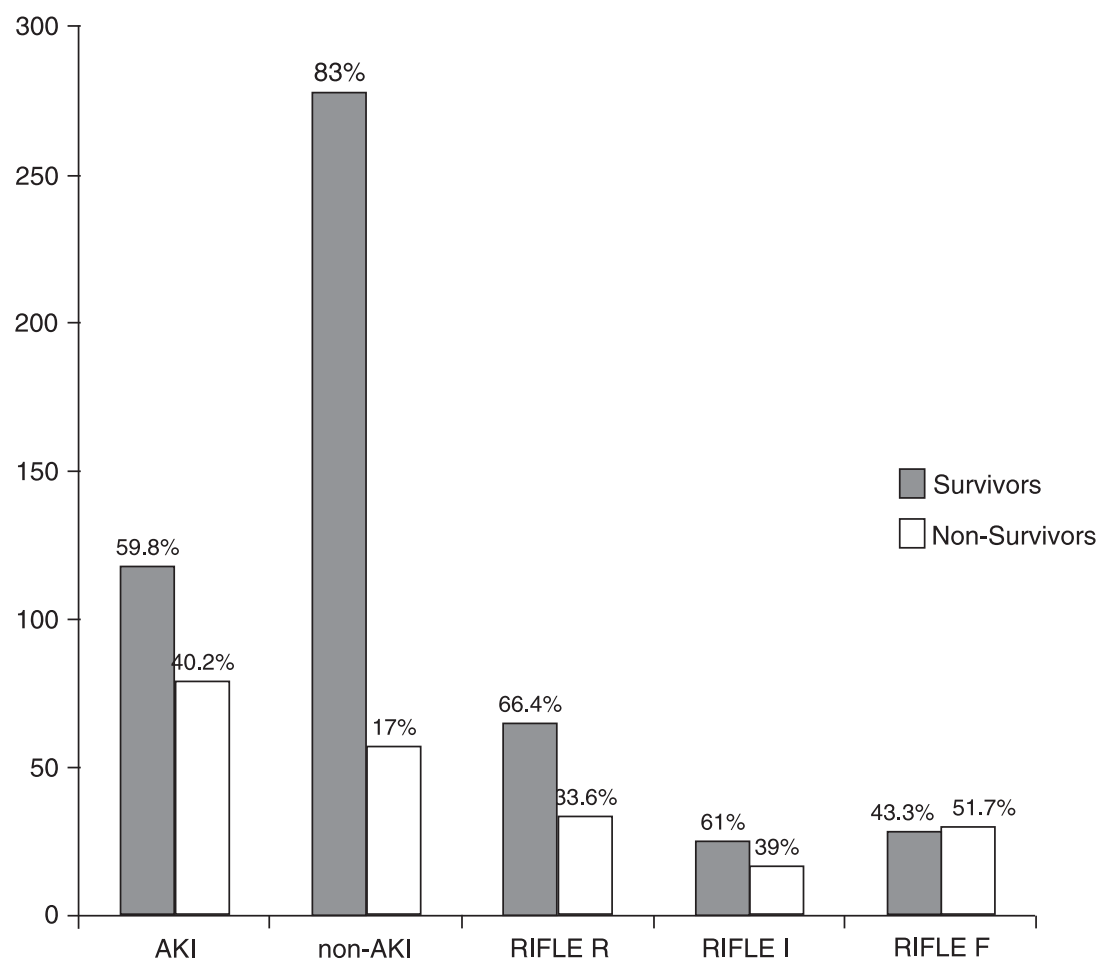

Figure 1. Mortality according to RIFLE classification: R (risk), I (injury), F (failure), L (loss), and $\mathrm{E}$ (end-stage renal disease), AKI = acute kidney injury, comparing survivors and non-survivors. Lopes et al. (19) studied the frequency of AKI among $240 \mathrm{HIV}$ patients and reported an incidence of $13.7 \%$. In the present study, the number of survivors 1 month after an AKI episode was low (15.2\%). In a Spanish study on $27 \mathrm{HIV}$-infected patients with glomerulonephritis, AKI was observed in $59.3 \%$ of cases (20). Peraldi et al. (21), in a retrospective study of 92 HIV patients, found as the main causes of AKI hemolytic-uremic syndrome (34\%), acute tubular necrosis (19.5\%), HIVAN (15.2\%), drug nephrotoxicity (14.1\%), and rhabdomyolysis (6.5\%). Among ambulatory HIV patients, AKI is caused mainly by drug nephrotoxicity. Some drugs can induce acute crystal kidney injury and acute interstitial nephritis. The more common drugs that cause crystal AKI are indinavir and sulfadiazine (14). Acute interstitial nephritis can be secondary to the use of sulfamethoxazole, trimethoprim, penicillins, and cephalosporins (18).

AKI was more frequent among males ( $83 \%$ of cases), as observed in the majority of AKI studies. Risk factors for AKI were male gender, fever, weight loss, diarrhea, non-use of antiretroviral drugs, anemia, and elevated liver enzymes. Other studies found male gender, advanced age, diabetes, chronic kidney disease, non-use of antiretroviral agents, HIV-advanced infection and co-infection by hepatitis $\mathrm{C}$ as risk factors for AKI in $\operatorname{HIV}(5,10)$. Emem et al. (17) reported advanced age, body mass index and CD4 count to be risk

factors associated with AKI in HIV patients. There was no difference regarding gender in this study. Diarrhea is an important symptom observed in HIV patients, mainly due to opportunistic infections, as is a known cause of AKI (prerenal component). An interesting finding of this research was that non-use of antiretroviral drugs was associated with a higher incidence of AKI, maybe due to the non-controlled HIV infection, which favors the occurrence of opportunistic diseases that can complicate with AKI. The other factors (weight loss, anemia and elevated liver enzymes) point to the presence of severe diseases, mainly opportunistic infections, that can cause AKI.

In the present study, increasing severity of $\mathrm{AKI}$ as measured by RIFLE classification was directly associated with higher mortality. Patients classified as "F" presented the highest risk for death $(\mathrm{OR}=5.1)$ in comparison with "I" $(O R=3.0)$ and "R" $(O R=2.4)$. The mortality of patients in the " $F$ " class was $51 \%$, which was higher than that observed in classes "I" (39\%) and "R" (33\%), showing that RIFLE classification is an important outcome predictor in AIDS patients. This classification was created in 2004 due to the necessity of unifying a classification for AKI, and it is now the most accepted definition for AKI (7). A significant association of this classification with mortality was demonstrated in other studies (22-24). Ricci et al. (9), in a 
meta-analysis, reviewed data from 24 studies with 71,000 patients and found a progressive increase in mortality along with RIFLE classification, ranging from a risk of death of 2.4 in patients classified as "Risk" to 6.3 in patients in "Failure" $(P<0.0001)$. There are few studies assessing this criterion in HIV patients. In a study performed in Portugal on $97 \mathrm{HIV}$ patients, RIFLE classification was significantly associated with death $(50 \%$ mortality in patients classified as "Risk", $66 \%$ in patients classified as "Injury" and $72 \%$ in patients classified as "Failure", P < 0.0001) (6). Other studies have shown that $\mathrm{AKI}$ is associated with an increase in mortality, and the RIFLE criterion was better than the APACHE II score to predict outcome in critically ill patients (25).

In the present study, overall mortality was $25 \%$, and the mortality rate was significantly higher among patients with $\mathrm{AKI}(40 \%)$, indicating that $\mathrm{AKI}$ is associated with a worse prognosis in AIDS patients. AKI mortality has been stable over the past years, despite advances in therapeutics, and varies from 7 to $80 \%$ depending on the study (26-28). Williams et al. (12), in a study on 13 HIV patients with kidney diseases, reported a higher mortality rate $(69.2 \%)$, and

\section{References}

1. Fine DM, Perazella MA, Lucas GM, Atta MG. Kidney biopsy in HIV: beyond HIV-associated nephropathy. Am J Kidney Dis 2008; 51: 504-514.

2. Rao TK. Human immunodeficiency virus (HIV) associated nephropathy. Annu Rev Med 1991; 42: 391-401.

3. Gupta SK, Eustace JA, Winston JA, Boydstun II, Ahuja TS, Rodriguez RA, et al. Guidelines for the management of chronic kidney disease in HIV-infected patients: recommendations of the HIV Medicine Association of the Infectious Diseases Society of America. Clin Infect Dis 2005; 40: 15591585.

4. Franceschini N, Napravnik S, Eron JJ Jr, Szczech LA, Finn WF. Incidence and etiology of acute renal failure among ambulatory HIV-infected patients. Kidney Int 2005; 67: 15261531.

5. Wyatt CM, Klotman PE. HIV-associated nephropathy in the era of antiretroviral therapy. Am J Med 2007; 120: 488492.

6. Lopes JA, Fernandes J, Jorge S, Neves J, Antunes F, Prata MM. An assessment of the RIFLE criteria for acute renal failure in critically ill HIV-infected patients. Crit Care 2007; 11: 401.

7. Kellum JA, Bellomo R, Ronco C. Classification of acute kidney injury using RIFLE: What's the purpose? Crit Care Med 2007; 35: 1983-1984.

8. Bellomo R, Kellum JA, Ronco C. Defining and classifying acute renal failure: from advocacy to consensus and validation of the RIFLE criteria. Intensive Care Med 2007; 33: 409-413.

9. Ricci Z, Cruz D, Ronco C. The RIFLE criteria and mortality in acute kidney injury: A systematic review. Kidney Int 2008; 73: $538-546$.

10. de Silva TI, Post FA, Griffin MD, Dockrell DH. HIV-1 infection and the kidney: an evolving challenge in HIV medicine. Mayo death was attributed to kidney disease in $23 \%$ of the cases. The presence of AKI has a big impact on the long-term outcome of patients. Triverio et al. (29), in a recent study on 206 patients with $\mathrm{AKI}$, observed a $46 \%$ rate of patient survival 90 days after hospital discharge and a mortality rate of $50 \%$ in 3 years for those with pre-existing renal disease prior to hospital admission.

$\mathrm{AKI}$ is a frequent complication in AIDS patients, which is associated with increased mortality. There are important markers for AKI in AIDS patients, such as thrombocytopenia and elevation of liver enzymes, which must be promptly recognized for the institution of early and adequate therapeutic measures. RIFLE classification is an important indicator of poor outcome in AIDS patients.

\section{Acknowledgments}

We are very grateful to the team of physicians, nurses, and medical students of the São José Hospital of Infectious Diseases for the assistance provided to the patients. Research supported by CNPq.
Clin Proc 2007; 82: 1103-1116.

11. Izzedine H, Baumelou A, Deray G. Acute renal failure in HIV patients. Nephrol Dial Transplant 2007; 22: 2757-2762.

12. Williams DI, Williams DJ, Williams IG, Unwin RJ, Griffiths $\mathrm{MH}$, Miller RF. Presentation, pathology, and outcome of HIV associated renal disease in a specialist centre for HIVIAIDS. Sex Transm Infect 1998; 74: 179-184.

13. Cohen SD, Chawla LS, Kimmel PL. Acute kidney injury in patients with human immunodeficiency virus infection. Curr Opin Crit Care 2008; 14: 647-653.

14. Kalim S, Szczech LA, Wyatt CM. Acute kidney injury in HIVinfected patients. Semin Nephrol 2008; 28: 556-562.

15. Wyatt CM, Morgello S, Katz-Malamed R, Wei C, Klotman $\mathrm{ME}$, Klotman PE, et al. The spectrum of kidney disease in patients with AIDS in the era of antiretroviral therapy. Kidney Int 2009; 75: 428-434.

16. Laguna-Torres VA, dos Reis MA, Menegaz RA, Pela GA, Prata A. [Renal anatomopathological changes in patients with acquired immunodeficiency deficiency syndrome]. Rev Soc Bras Med Trop 1998; 31: 465-472.

17. Emem CP, Arogundade F, Sanusi A, Adelusola K, Wokoma F, Akinsola A. Renal disease in HIV-seropositive patients in Nigeria: an assessment of prevalence, clinical features and risk factors. Nephrol Dial Transplant 2008; 23: 741-746.

18. Ross MJ, Klotman PE, Winston JA. HIV-associated nephropathy: case study and review of the literature. AIDS Patient Care STDS 2000; 14: 637-645.

19. Lopes GS, Marques LP, Rioja LS, Basilio-de-Oliveira CA, Oliveira AV, Nery AC, et al. Glomerular disease and human immunodeficiency virus infection in Brazil. Am J Nephrol 1992; 12: 281-287.

20. Gutierrez E, Morales E, Gutierrez ME, Manzanares MJ, Rosello G, Merida E, et al. [Glomerulopathies associated to HIV infection: a Spanish perspective]. Nefrologia 2007; 27: 439-447. 
21. Peraldi MN, Maslo C, Akposso K, Mougenot B, Rondeau E, Sraer JD. Acute renal failure in the course of HIV infection: a single-institution retrospective study of ninety-two patients and sixty renal biopsies. Nephrol Dial Transplant 1999; 14: 1578-1585.

22. Hoste EA, Kellum JA. Incidence, classification, and outcomes of acute kidney injury. Contrib Nephrol 2007; 156: 32-38.

23. Ahlstrom A, Kuitunen A, Peltonen S, Hynninen M, Tallgren M, Aaltonen $\mathrm{J}$, et al. Comparison of 2 acute renal failure severity scores to general scoring systems in the critically ill. $A m \mathrm{~J}$ Kidney Dis 2006; 48: 262-268.

24. Abosaif NY, Tolba YA, Heap M, Russell J, El Nahas AM. The outcome of acute renal failure in the intensive care unit according to RIFLE: model application, sensitivity, and predictability. Am J Kidney Dis 2005; 46: 1038-1048.
25. Barrantes F, Tian J, Vazquez R, Amoateng-Adjepong $\mathrm{Y}$, Manthous CA. Acute kidney injury criteria predict outcomes of critically ill patients. Crit Care Med 2008; 36: 1397-1403.

26. Ympa YP, Sakr Y, Reinhart K, Vincent JL. Has mortality from acute renal failure decreased? A systematic review of the literature. Am J Med 2005; 118: 827-832.

27. Joannidis $M$, Metnitz PG. Epidemiology and natural history of acute renal failure in the ICU. Crit Care Clin 2005; 21: 239-249.

28. Utas C, Yalcindag C, Taskapan H, Guven M, Oymak O, Yucesoy M. Acute renal failure in Central Anatolia. Nephrol Dial Transplant 2000; 15: 152-155.

29. Triverio PA, Martin PY, Romand J, Pugin J, Perneger T, Saudan P. Long-term prognosis after acute kidney injury requiring renal replacement therapy. Nephrol Dial Transplant 2009; 24: 2186-2189. 